\section{Fair Is Not Fair Everywhere}

\author{
Marie Schäfer', Daniel B. M. Haun ${ }^{1,2,3}$, and \\ Michael Tomasello ${ }^{1}$ \\ ${ }^{1}$ Department of Developmental and Comparative Psychology, Max Planck Institute for Evolutionary \\ Anthropology, Leipzig, Germany; ${ }^{2}$ Max Planck Institute for Psycholinguistics, Nijmegen, The Netherlands; \\ and ${ }^{3}$ Department of Psychology, University of Jena
}

Psychological Science 2015, Vol. 26(8) 1252-1260 (C) The Author(s) 2015 Reprints and permissions: sagepub.com/journalsPermissions.nav DOI: $10.1177 / 0956797615586188$ pss.sagepub.com

\begin{abstract}
Distributing the spoils of a joint enterprise on the basis of work contribution or relative productivity seems natural to the modern Western mind. But such notions of merit-based distributive justice may be culturally constructed norms that vary with the social and economic structure of a group. In the present research, we showed that children from three different cultures have very different ideas about distributive justice. Whereas children from a modern Western society distributed the spoils of a joint enterprise precisely in proportion to productivity, children from a gerontocratic pastoralist society in Africa did not take merit into account at all. Children from a partially hunter-gatherer, egalitarian African culture distributed the spoils more equally than did the other two cultures, with merit playing only a limited role. This pattern of results suggests that some basic notions of distributive justice are not universal intuitions of the human species but rather culturally constructed behavioral norms.
\end{abstract}

\title{
Keywords
}

cross-cultural differences, morality, distributive justice, equity, children, peer interactions

Received 7/23/14; Revision accepted 4/17/15

When the question is how to distribute resources, issues of justice and fairness naturally arise (Rawls, 1971). Most straightforwardly, a person attempting to distribute resources fairly may consider each recipient as equally deserving or may determine that those in need deserve more resources to bring them up to an equal level with those not in need. In cases when goods are produced as a result of joint effort, a fair distributor may also use some kind of merit-based distribution that reflects the productivity of recipients in an attempt to distribute an equal reward for each unit of work. Principles that take into account specific factors such as merit-as principled variations on the theme of equality-are often called principles of equity (Adams, 1963).

Humans have been shown to be markedly averse to inequity (someone gets more than others or more than he or she deserves), caring greatly that spoils are shared fairly (e.g., Dawes, Fowler, Johnson, McElreath, \& Smirnov, 2007; Fehr \& Gächter, 2000). This is particularly true when resources are acquired jointly. For example, when judging the fairness of distributions or when allocating resources among third parties, people from many societies consider the amount of work contributed toward resource production and prefer equitable distributions (Fischer \& Smith, 2003; Marshall, Swift, Routh, \& Burgoyne, 1999). When sharing rewards for work with a coworker, people will often try to restore equity by redistributing resources in proportion to work contribution even when doing so means that they receive the smaller share (Almås, Cappelen, Sørensen, \& Tungodden, 2010; Frohlich, Oppenheimer, \& Kurki, 2004; Miller \& Komorita, 1995; Oxoby \& Spraggon, 2008).

Although the evidence for the prevalence of meritbased distribution is strong, it is not yet clear whether such notions of fairness are equally important across human societies. If human sensitivity to fairness is rooted in psychological adaptations that support the cooperative production of resources, then it is reasonable to posit that

\footnotetext{
Corresponding Author:

Marie Schäfer, Max Planck Institute for Evolutionary Anthropology, Department of Developmental and Comparative Psychology,

Deutscher Platz 6, 04103 Leipzig, Germany

E-mail: mschaefer@eva.mpg.de
} 
some principles of justice could indeed be universal (Baumard, Mascaro, \& Chevallier, 2012; Robinson, Kurzban, \& Jones, 2007). On the other hand, research conducted outside of Western societies has demonstrated a great degree of cultural variation concerning distributive justice and suggests that some beliefs concerning fairness may be driven by socially acquired norms (Chudek \& Henrich, 2011; Henrich et al., 2010). For example, while people in many societies take merit into consideration, people from some cultures are more strongly concerned with interpersonal harmony and need when judging the fairness of distributions (Carson \& Banuazizi, 2008; Murphy-Berman, Berman, Singh, Pachauri, \& Kumar, 1984; Nisan, 1984).

Evidence in support of the prominence of merit as a factor in notions of justice comes from studies showing that in Western countries, basic intuitions regarding meritbased fairness develop very early in childhood. While preschoolers may typically still espouse principles of equality (all people get the same resources) when verbally interviewed about notions of justice (Damon, 1977), or favor themselves when sharing rewards with unknown partners working in a different room (Hook \& Cook, 1979; Lane \& Coon, 1972), children as young as 3 years of age do acknowledge differences in merit when distributing resources in less-demanding scenarios. For instance, when prompted to allocate a reward that cannot be divided equally, 3-year-olds prefer to give the bigger portion to the harder-working individual (Baumard et al., 2012). When sharing rewards for work with a peer, 3 -year-olds also share more with partners who worked harder than with partners who worked less (Hamann, Bender, \& Tomasello, 2014; Kanngiesser \& Warneken, 2012). After they enter school, children begin using meritbased notions of equity in an adult manner, acknowledging that more-productive workers deserve more of any resources produced, even when such norms conflict with their own interests (Hook \& Cook, 1979). Notably, studies investigating children's ideas of fairness in windfall scenarios (i.e., outside of resource production) have found cultural differences already very early in development, as young as 3 years of age (Rochat et al., 2009). Furthermore, cultural variation seems to become particularly pronounced around early school age when children begin behaving more like adults in their societies when distributing resources (House et al., 2013).

No study has looked at how young children (or adults) from different cultures take merit into account when sharing rewards. In particular, notions of distributive justice have not been studied in small-scale, traditional societies in which many goods are produced and exchanged among familiar group members (Gurven, 2004). In the current study, therefore, we looked at the tendencies of children from three very different societies to use principles of merit when dividing jointly earned resources. One group of children was from a Western country (Germany). A second group was from an egalitarian forager society that relies on gathering bush food for subsistence: the $\neq$ Akhoe Hai $\|$ om in Namibia (Widlok, 1999). Egalitarian forager societies are characterized by a high degree of equality among group members, which is actively maintained by social norms that discourage the accumulation of wealth and status, for example, by promoting sharing and modesty with regard to acquired resources (Woodburn, 1982). In such a society, meritbased distributions could be disruptive, creating inequalities within relationships.

A third group of children was from a pastoralist society, also from rural Africa, that traditionally relies on keeping livestock for subsistence: the Samburu in Kenya (Spencer, 1965/2004). Samburu society is characterized by a gerontocracy - a strict age-based hierarchy in which group elders hold most of the wealth and power within communities and make many decisions about the administration of work and resources autocratically. Children in this culture might have comparatively little experience with merit-based divisions because resource distributions seem to be mainly determined by authority and status (for more details on the two African societies, see the background information in the Supplemental Material available online). We hypothesized that whereas German children may consider work-based merit from an early age, children from the two small-scale societies might be less concerned with merit and possibly apply different distributive norms (e.g., equality) when sharing among peers.

In this study, pairs of children (4-11 years old) played a game for rewards in which they fished magnetic cubes out of two containers. The game was rigged so that in the key unequal-merit condition, one child fished out three times as many cubes as the other (9:3). In two control conditions, children either fished out an equal number of cubes (6:6; equal merit) or did not fish at all but were simply given unequal numbers of cubes $(9: 3$; no merit). In all conditions, the two children received a plastic tube that contained a number of rewards equal to the total number of cubes they had obtained together (12) and were left alone to divide the rewards between themselves.

If children took merit into consideration when dividing the rewards, those who fished out the same number of cubes should divide the rewards equally, whereas if each child fished out a different number of cubes, there should be an unequal division of rewards favoring the child who contributed more. Furthermore, distributions should not be based on the number of cubes in the nomerit condition, since cubes were not the result of effort but simply assigned to children by the experimenter. 


\section{Method}

\section{Participants and design}

Participants were one hundred fifty-five 4 - to 11-year-old children from three cultural settings: $45 \neq$ Akhoe Hai $\|$ om children (24 girls, 21 boys; mean age $=7.7$ years, $S D=$ 1.8), 54 Samburu children ( 28 girls, 26 boys; mean age $=$ 7.6 years, $S D=2.0$ ), and 56 children from Germany ( 28 girls, 28 boys; mean age $=7.3$ years, $S D=1.7) .{ }^{1}$

The $\neq$ Akhoe Hai || om (henceforth Hai $\mid$ om) children lived in a small community in a remote rural area of northern Namibia (local population 200). Main sources of income for families were gathering bush food, state pensions, and occasional wage work at the nearby farm. All participating children were native speakers of $\neq$ Akhoe Hai |l om and had the possibility to attend a local school in which they were taught in English and their mother tongue. Fifty-one percent of participants were enrolled in school, $38 \%$ went to the adjacent preschool, and $11 \%$ did not attend any educational program.

The Samburu children came from a remote, rural region in north-central Kenya (local population 600). Main sources of income were the livestock owned by families, seasonal gardening by women, and occasional wage work by men. The participating children were native speakers of Samburu and were taught in Kiswahili and English at school. Eighty-one percent of the participants attended the community school, and 19\% attended the adjacent preschool.

The German children lived in the same neighborhood of a suburban municipality (local population 24,000). Families came from mixed socioeconomic backgrounds, and most parents engaged in paid work. All participating children were native speakers of German and went to the same elementary school (71\%) or nearby preschool (29\%). In all three study locations, children's participation in the study was strictly voluntary and took place with previous consent by parents, teachers, or local authorities.

Children participated in the study in dyads; each child was randomly paired with a familiar same-sex peer. Within dyads, the median age difference for all cultures was 0 years ( 95 th percentile $=1$ year), with a maximum difference of 1 year for Germans and 2 years for Hai $\|$ om and Samburu. Children took part in all three conditions, on 3 separate days, but each time paired with a new partner. The session in which each condition took place was counterbalanced. All three sessions took place within 2 weeks.

Because the African portion of the study was conducted in very small, remote communities, the number of available children in the respective age range was limited, in particular in Namibia (only 45 Hai $\|$ om children were available). On the basis of a pilot study conducted in Germany, we determined that a minimum sample size of 20 to 28 dyads per condition would be needed. In the Hai $\|$ om community, we could test a maximum of 22 dyads per condition (based on 45 children), and in the Samburu community, we could test a maximum of 27 dyads (based on 54 children). In Germany, we adapted the sample size to the number of children available in the two African sites, testing the maximum 28 dyads per condition (combining 56 children). Because of unexpected long absences from the community or school (as a result of illness or long-term leaves), 7 Hail| om, 2 Samburu, and 6 German children could participate only in two conditions, and 1 Samburu and 3 German children in only one condition. Therefore, in total, 64 Hai $\|$ om, 79 Samburu, and 78 German pairs were tested (for a complete overview, see Table S1 in the Supplemental Material available online). Two additional dyads (one German and one Hai $\|$ om) could not be included because of camera failure and experimenter error, respectively.

\section{Materials}

The study was conducted in an empty classroom. A big box $(50 \times 60 \mathrm{~cm})$ served as a table at which the interaction took place. Food items that were highly attractive (e.g., dried fruits, cereals, sweets) were used as rewards. Each child received a transparent plastic cup with a lid for collecting the rewards obtained during the study. Rewards were given to children inside a long, transparent tube $(30 \times 2.7 \mathrm{~cm})$. Because rewards were stacked inside and fell out one by one, this container enabled children to better visualize the quantity and slowed down the distribution process (ensuring enough time for negotiations).

The apparatus for the fishing game consisted of two magnetic fishing rods (angle-forming wooden sticks $22 \mathrm{~cm}$ long with a magnet at one end) and two fishing tanks (narrow, transparent boxes $28 \times 24 \times 4 \mathrm{~cm}$ ). The tanks were filled with little cubes $(2 \times 2 \times 2 \mathrm{~cm})$ whose surface had been coated with metallic paint and then covered with blue plastic film. To create the different work conditions, we manipulated the cubes without children noticing. All cubes looked identical and were attracted to the magnetic rods; however, some cubes were a little less magnetic than others and fell off more easily. In the equalmerit condition, both children's tanks contained the same amount of cubes that could be fished out ( 6 of 18); thereby, children obtained the same cube score (6:6). In the unequal-merit condition, the high-merit child's tank was filled with more cubes that could be fished out completely ( 9 of 18 ) than the other child's tank ( 3 of 18), and children therefore obtained different cube scores (9:3). The cubes that each child fished out were stored inside two score pillars (narrow boxes $27.5 \mathrm{~cm}$ high, $4 \times 4 \mathrm{~cm}$ wide, with a transparent front). Cubes formed a tower inside, so children could compare their scores visually. 


\section{a}

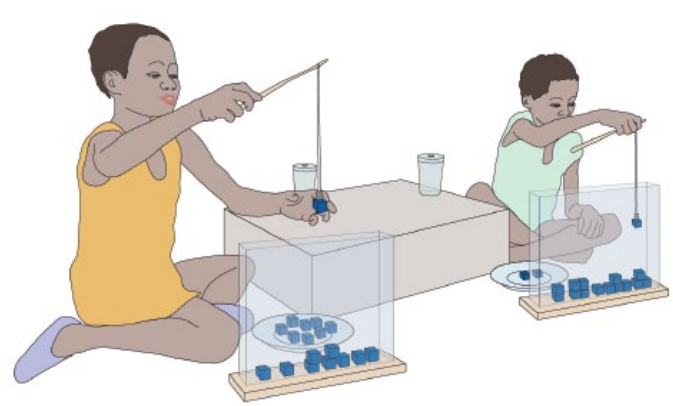

b

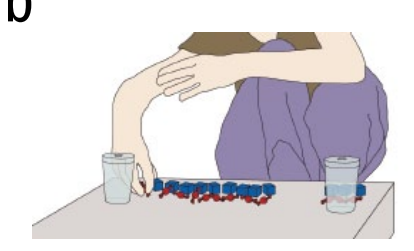

C

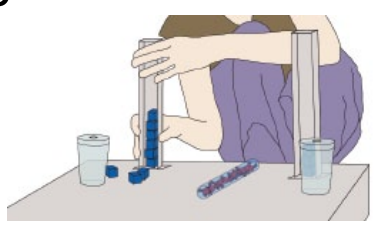

d

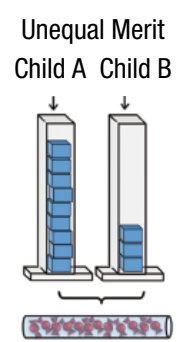

Equal Merit

Child A Child B
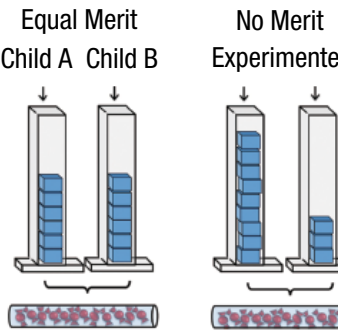

Experimenter

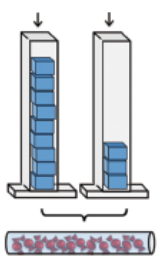

e

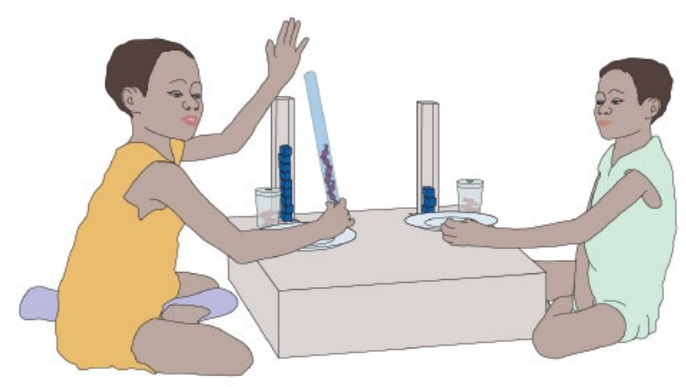

Fig. 1. Study procedure. Children assigned to dyads fished cubes out of tanks in the unequal- and equal-merit conditions ( $a$; in the no-merit condition, the experimenter fished out the cubes for the children). The experimenter then counted the total of 12 cubes obtained by or allocated to each dyad and assigned the dyad a corresponding number of rewards (b). Next, the experimenter placed the rewards in a reward tube and the cubes in each child's score pillar (c). In the two merit conditions, she gave each child the number of cubes he or she had fished out (d), whereas in the no-merit condition, she distributed the 12 cubes unequally. Children extracted the 12 rewards from the reward tube one at a time and divided them between each other as they saw fit (e).

In all three cultures, the same instructions were given to children in their mother tongue by using videos. The instructions were translated from English into the local language ( $\neq$ Akhoe Hai $\|$ om, Samburu, German) by a native speaker and checked for accuracy via a back-translation by another speaker. In the videos, an adult demonstrated the basic actions of the game while a native speaker read the instructions aloud. In Video 1, the actor demonstrated how to use the fishing rod for fishing out cubes. In Video 2 , children were informed about the game, in particular that they had to quickly fish as many cubes as possible out of the tanks and that they would receive rewards for all fished-out cubes. Video 3 explained how the experimenter would provide exactly one sweet per fished cube (for video instructions, see the Supplemental Material).

\section{Procedure}

At the start of the session, the experimenter seated the children opposite each other at the small table. Each child received a collection cup (labeled with his or her name) and three rewards to put inside. The first time children participated, the experimenter showed Video 1, and the children could try out the fishing materials. After the warm-up, the fishing game was played (Fig. 1). In the equal-merit and unequal-merit conditions, the experimenter placed a tank filled with cubes in front of each child and showed Video 2 (twice during the first session). Each child then received a fishing rod, and the experimenter announced "Go!" When children had fished out the maximum number of cubes in their condition (6:6 or 9:3), the experimenter called "Stop!" and took away the rods and tanks. In the no-merit condition, children did not fish out cubes themselves. Instead, the experimenter fished 12 cubes out of one tank by herself.

In all three conditions, the experimenter placed the 12 cubes (that were either fished out by the children or the experimenter) on the table and showed Video 3 (twice during the first session). After the video, she placed one sweet in front of each cube while counting them and then put all 12 rewards (corresponding to the total number of 12 cubes) inside the transparent reward tube, which was placed in the middle of the table (Figs. 1b and 1c).

In the unequal- and equal-merit conditions, the experimenter counted the portion of the 12 cubes that each child had fished out while placing the cubes in each child's score pillar. In the no-merit condition, she simply distributed the 12 cubes unequally (9:3) into the two score pillars. The score pillars remained on the table throughout the rest of the session as a reminder of the cube scores (see Fig. 1d for cube score in each condition). Finally, the experimenter placed the reward tube with the 12 rewards in the middle between the two children. She told the children to put the rewards from the tube in their collection cups and left the room. Children were left alone for at least $2 \mathrm{~min}$ and until all 12 rewards were distributed (Fig. 1e). The session ended by giving each child the rewards from his or her cup. 


\section{Coding and data analysis}

Sessions were video-taped, and we coded from video how many rewards (of the 12 in total) each child had in his or her cup by the end of the session. For reliability, $20 \%$ of videos were coded by a second observer who was blind to hypotheses and conditions. There was an almost perfect correlation (Spearman's $\rho=0.9, p<.0001$ ) and no notable difference (Wilcoxon rank test, $N=44$, $p=1$ ) in coding. The total number of distributed rewards occasionally differed from 12 because children divided one sweet into two halves (six cases), children fished out more cubes than intended (eight cases), or one sweet got lost accidentally during distribution (five cases).

To test whether contributing with equal versus unequal merit had an effect on how equally children shared the rewards, we calculated the absolute difference between the final shares of the two children in each session. A Poisson generalized linear mixed model analysis (Baayen, 2008; McCullagh \& Nelder, 2008) was conducted on the absolute difference to test the effects of the two merit conditions, culture, and age (including interactions) while controlling for sex, session, the total number of distributed rewards (offset variable), and the random effects of individuals. To test the significance of the test variables overall (Forstmeier \& Schielzeth, 2011) and of interactions and factors with multiple levels, we compared models with and without the respective effect using likelihoodratio tests (Dobson, 2010). Significant interactions were followed up with post hoc negative-binomial generalized linear models (GLMs) within each merit condition.

To test whether children divided the rewards according to cube score, we used binomial tests to establish whether the probability of the high-scoring child getting more than half was greater than .387 (the sum of all probabilities for outcomes favoring the high-scoring child). For groups in which this probability was above chance, two linear models were created: one on the deviation of the high-merit child's share from the equal split and one on the deviation from the cube score when sharing according to merit. In these linear models, age, sex, and session were entered in scaled form (scaled to a mean of zero) so that the model intercepts for each reference level of culture indicated whether the average share of the respective cultural group deviated significantly from the equal split (or the cube score) when controlling for all scaled variables. All analyses were conducted in R ( $\mathrm{R}$ Development Core Team, 2013) using the packages MASS and lme 4 (Bates, Maechler, Bolker, \& Walker, 2013; Venables \& Ripley, 2002).

\section{Results}

The primary question was whether children in three cultures would consider merit (understood as the number of cubes fished out of the boxes) when dividing the 12 rewards. If children considered merit, they should have divided the 12 rewards more equally ( 6 rewards each or only a small difference between their shares) in the equal-merit condition and more unequally (more than 6 for one child) in the unequal-merit condition. The greater portion of the 12 rewards should have been allocated to the child who had fished out 9 of the 12 cubes in the unequal-merit condition and possibly match the number (9) exactly. Furthermore, if children were truly concerned about merit, as is implied by their attention to the unequal number of cubes provided per individual in the unequalmerit condition, their division of the rewards should not consistently favor the child with the higher cube score in the no-merit condition, in which children were simply given unequal numbers of cubes ( 3 and 9) freely, without any work.

We hypothesized that German children (growing up in a Western society) would consider merit and share the rewards on the basis of the number of fished-out cubes, even when this meant that they would have to divide the rewards very unequally (e.g., 9 and 3 in the unequalmerit condition). In contrast, children from the two smallscale societies (Hai $\|$ om and Samburu) might be less concerned with differences in merit and apply different distributive norms, such as equality, even when contributions were unequal.

We first analyzed whether contributing equal or unequal numbers of cubes had any effect on how equally children shared the rewards (in terms of the difference between children's takes within dyads). Samburu children varied greatly in how they divided the 12 rewards, from no sharing at all (e.g., one child monopolized all 12 rewards from the reward tube) to exactly equal sharing (both children obtained 6 rewards). In the two merit conditions, only a minority of Samburu pairs divided the rewards exactly equally ( 6 of 27 pairs in the equal-merit condition and 1 of 26 pairs in the unequal-merit condition).

All Hai $\|$ om and German pairs in both merit conditions shared the 12 rewards such that both children in all dyads ended up with at least 3. When children had fished out equal numbers of cubes, the majority of pairs split the 12 rewards exactly equally in both groups (14 of 21 Hai $\|$ om and 24 of 26 German pairs). When children had fished out unequal numbers of cubes, 1 of the 2 children obtained a bigger portion of the rewards in the majority of cases (18 of $22 \mathrm{Hai} \| \mathrm{om}$ and 18 of 27 German pairs).

We conducted a Poisson generalized linear mixed model analysis testing the effect of equal versus unequal merit and its interactions with culture and age on the absolute difference between children's shares. This analysis revealed an overall significant effect of the tested variables-likelihood-ratio test: $\chi^{2}(11)=109.64, p<.0001$. In particular, there was a significant interaction between 

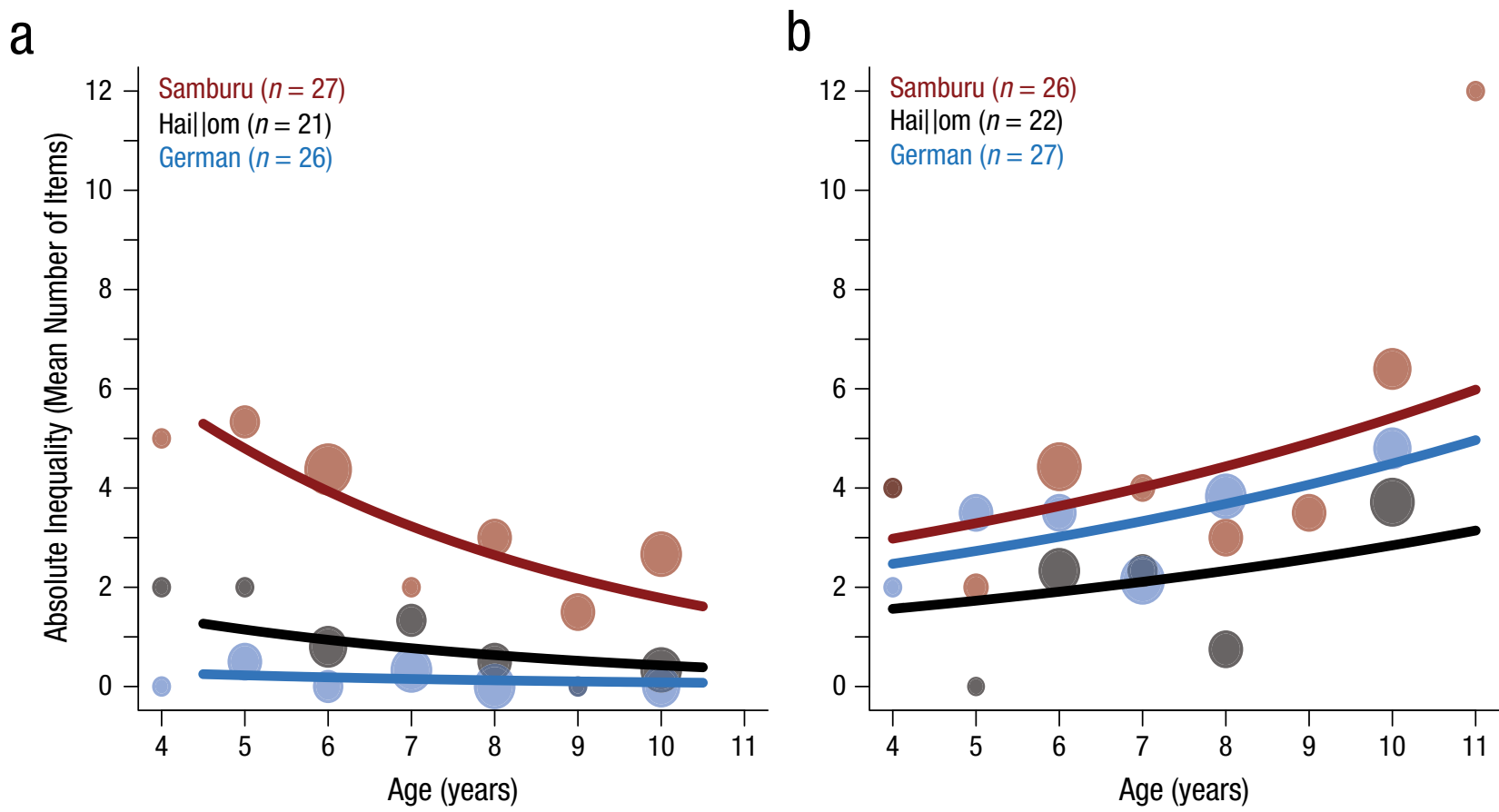

Fig. 2. Inequality of distribution (mean absolute difference between children's shares) as a function of age and culture in the (a) equalmerit and (b) unequal-merit conditions. The size of the bubbles is proportional to the respective number of pairs ( $n$ s refer to dyads).

merit condition and age-likelihood-ratio test: $\chi^{2}(1)=14.52$, $p<.001$-and between merit condition and culturelikelihood-ratio test: $\chi^{2}(2)=36.1, p<.0001$. All other tested effects were not significant (for all model results, see Table S2 in the Supplemental Material). As Figure 2 shows, across cultures, children produced more equal divisions with greater age if they contributed with equal merit (GLM within the equal-merit condition: estimate for age $=-0.41,{ }^{2} S E=0.15, p=.006$ ) and more unequal divisions with greater age when they had contributed with unequal merit (GLM within the unequal-merit condition: estimate for age $=0.17, S E=0.09, p=.050$ ) .

However, as indicated by the significant interaction between merit condition and culture, children in the three cultures differed in the way in which contributing equally versus unequally influenced their division of rewards. Samburu children shared most unequally in both merit conditions (see Fig. 2) and, in particular, significantly more unequally than German children (GLM estimate $=3.11, S E=0.55, p<.0001)$ and Hai $\|$ om children (GLM estimate $=1.54, S E=0.36, p<.0001)$ when they had contributed equally to obtaining the rewards in the equal-merit condition. In contrast, of the three cultures, Hai || om children shared the rewards most equally, even in the unequal-merit condition, and they did so significantly more equally than did Samburu children (estimate $=0.65, S E=0.22, p=.003$ ) and German children (estimate $=0.46, S E=0.23, p=.044)$. German children distinguished most between the two merit conditions: They shared most equally when rewards had been obtained through equal merit, even more than Hai $\mid$ om children (GLM estimate $=-1.57, S E=0.61, p=.01$ ), but as unequally as Samburu children when contributions to the rewards had been unequal (GLM estimate $=-0.19$, $S E=0.2, p=.332$ ).

In the second step of the analysis, we tested whether the child who had fished out 9 of the 12 cubes in the unequal-merit condition would be favored with the bigger portion of the rewards. As Figure 3 shows, in the case of Samburu children, the child who had obtained 9 out of 12 cubes did not receive the bigger share of rewards more often than expected by chance (only $46 \%$ of cases; $p$ from binomial test $=.279$ ). In Samburu dyads, the highmerit child got 5 out of 12 rewards in 31\% of dyads, and in $50 \%$ of dyads, the high-merit child actually got less than half $(M d n=5.5)$. Thus, members of Samburu pairseven though they shared very unequally-did not divide up the rewards according to merit at all.

In contrast, when Hail|om children divided the rewards in the unequal-merit condition, the child who had fished out more cubes received the bigger share most of the time $(68 \%$ of cases; $p$ from binomial test $=$ .005). A linear model analysis on the deviation of the high-merit child's relative share from the equal split confirmed that his or her share was significantly above the equal share, on average (intercept: estimate $=0.07, S E=$ 


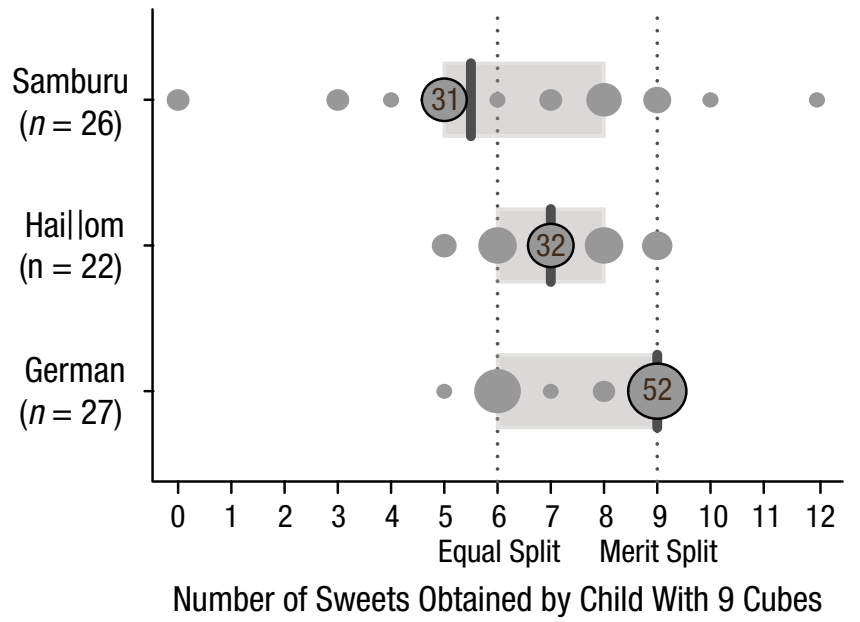

Fig. 3. Final share of rewards allocated to the children who fished out 9 of the 12 cubes in the unequal-merit condition, separately for each culture ( $n$ s refer to dyads). The size of the bubbles is proportional to the percentage of dyads. Bubbles with black borders indicate modes; numbers indicate the respective percentage of dyads. Solid lines and boxes indicate medians and quartiles, respectively.

$0.02, p=.005) .^{3}$ As shown in Figure 3, in Hai $\|$ om dyads, the mode was for the high-merit child to get 7 out of 12 rewards (in 32\% of dyads), and in the majority of dyads, the high-merit child got at least that much $(M d n=7)$. Thus, even though their distributions deviated least from equality, Hai || om children shared according to merit by favoring the child who had fished out three times more cubes with a little more of the rewards. Notably, Hai || om pairs did not match the distribution of rewards to the number of fished cubes: The linear model analysis on the deviation of the high-merit child's share from the cube score when sharing according to merit revealed that children who received a bigger share still received significantly less than suggested by the number of cubes they had fished out (intercept: estimate $=-0.11, S E=0.01, p<$ .0001 ; for all results of both linear models, see Table S3 in the Supplemental Material). Thus, Hai $\|$ om children rewarded merit, but they did not establish equity by sharing the rewards proportionally to merit.

Among the German pairs, the child who had fished out more cubes in the unequal-merit condition also received a bigger share in the majority of cases $(63 \%, p$ from binomial test $=.009$ ), and his or her relative share was significantly above the equal share, on average (intercept: estimate $=0.14, S E=0.02, p<.0001$ ). Moreover, high-merit children's share in German pairs was bigger than in Hai $\|$ om dyads (estimate for culture $=0.08, S E=$ $0.03, p=.016$ ). In fact, as Figure 3 shows, their shares actually matched the cube score in most of the cases: The mode and median was for high-merit children to receive 9 out of 12 rewards (in 52\% of dyads), exactly as many rewards as cubes they had fished out, and their average share did not significantly deviate from the cube score when sharing according to merit (intercept: estimate $=$ $-0.02, S E=0.01, p=.178$; for all linear model results, see Table S3 in the Supplemental Material). Thus, German children not only rewarded merit by favoring the greater contributor with a bigger share, but they actually used merit to establish equity by matching the distribution to contributions proportionally.

A comparison of Hai $\mid$ om and German children's divisions of rewards in the no-merit and unequal-merit condition suggests that the similarity between the number of cubes fished out and the number of rewards allocated in the unequal-merit condition was not the result of a simple bias but was truly based on children's consideration of performance. In the no-merit condition, in which cubes were not obtained through work but simply given to the children by the experimenter, children did not share rewards on the basis of cube score, as in this condition, the mode and the median in all three cultures was for the child with 9 cubes to get exactly half of the 12 rewards (35\% of Samburu, 38\% of Hai $\|$ om, and $68 \%$ of German pairs). Thus, the child with more cubes was not systematically favored with a bigger share when cube score was not the result of merit $(31 \%$ of cases for Samburu pairs, $p$ from binomial test $=.850 ; 38 \%$ of cases for Hai $\|$ om pairs, $p$ from binomial test $=.605 ; 32 \%$ of cases for German pairs, $p$ from binomial test $=.814$ ).

\section{Discussion}

These results suggest that ideas of distributive justice based on merit are not culturally universal. Young children-who are typically not producing or exchanging goods yet on a regular basis-adopt different cultural practices regarding the sharing of jointly earned resources, even when interacting with peers when no adult is present.

Cultural differences might stem from a variety of factors. We propose that our data could at least in part be explained by the fact that in large-scale societies (e.g., Germany), relationship-neutral norms might be particularly important for regulating transactions between individuals who do not share personal history or interact only temporarily in specific contexts. In such cultures, a focus on equitable interactions, especially when distributing resources that are produced through joint efforts, gains importance, as there may be no future encounters in which things could be evened out. In contrast, in many small-scale societies (e.g., Hai || om and Samburu), most exchanges take place between individuals familiar with one another and who repeatedly interact in various domains (Gurven, 2004; Gurven \& Winking, 2008). In such societies, norms applied to interactions might be more dependent on personal relationships than on 
impersonal standards. Thus, in such cultures, it may be more important to build and sustain long-term relationships based on equity than to establish equity within any single interaction.

In egalitarian forager societies such as the Hai $\|$ om, sharing among group members fulfills not only economic but also significant social functions. Hai $\|$ om society is characterized by egalitarian relationships, with authority and status playing only a limited role (Widlok, 1999). Sharing on "demand" can work as a leveling mechanism, balancing asymmetries in wealth and ensuring equality (Woodburn, 1982). Equal or balanced distributions are indeed highly valued among Hail| om adults, and demand sharing is widely practiced within the community (for adult views on sharing, see the background information in the Supplemental Material). Children may internalize such social values early on and apply them within their own interactions, as suggested by the results of the present study, in which Hai || om children avoided highly unequal distributions.

Children in different cultures may also have varied experience as to how adults distribute things. For example, in contrast to the Hai || om, many aspects of Samburu society are characterized by a strict age-based hierarchy (gerontocracy). Group elders are responsible for administrating and organizing work tasks and resources, and they make most of the important decisions within families and communities (Spencer, 1965/2004). Conflicts among group members are often solved by authorities such as the elders. Research using economic games has shown that authority can have an important influence on Samburu adults' decisions about resource distribution (Lesorogol, 2005). Thus, it may be that Samburu children have little experience making decisions concerning resource distribution themselves and that this inexperience led to the very unequal, but undirected, distributions in the present study.

It should be noted that in the current study, we tested children's consideration of merit on the basis of pure productivity or achievement without distinguishing between different causes for differences in outcome (e.g., between effort and skill). In Western societies, people often hold others responsible for their achievements as much as for their invested effort or time when distributing resources (Almås et al., 2010; Cappelen, Sørensen, \& Tungodden, 2010). It is possible that in other cultures, such as the traditional societies in our study, children (and adults) have different ideas about what aspects of merit should be considered in resource distribution.

It is likely that there are some universals concerning distributive justice across human cultures. It is difficult to imagine a culture that would reward sloth over hard work, for example, or a culture in which there are no principles for determining merit at all. It is possible that in all cultures there are also some basic principles of equity even if they are not determined by merit or evident within single interactions-such principles may include gender, age, political status, or religious affiliation. In any case, this study demonstrates that there are important cultural differences in notions of merit in distributive-justice situations and that these differences are already evident in young children's interactions with peers outside of any immediate adult influence. There remains much to be learned about the many dimensions of human morality and how they may vary in the human species.

\section{Author Contributions}

M. Schäfer developed the study concept. M. Schäfer, D. B. M. Haun, and M. Tomasello designed the study and wrote the manuscript, to which the last two authors contributed equally. M. Schäfer conducted the study and analyzed the data.

\section{Acknowledgments}

We thank all children and teachers in Kenya, Namibia, and Germany for their participation. We thank R. Lesowapir, his family, and the Golgoltim community (Kenya), as well as C. Rapold, D. Tjizao, E. Kavetuna, C. Khamkaib, and the Farm 6 community (Namibia) for their support. We appreciate the approval by the Working Group of Indigenous Minorities in Southern Africa and the National Council for Science and Technology (Kenya) for allowing us to conduct our research. We thank P. Richter and J. Johe for assistance, M. Sureck for graphics, and R. Mundry for statistical advice.

\section{Declaration of Conflicting Interests}

The authors declared that they had no conflicts of interest with respect to their authorship or the publication of this article.

\section{Supplemental Material}

Additional supporting information can be found at http://pss .sagepub.com/content/by/supplemental-data

\section{Notes}

1. Birth records were not available for Hai $\|$ om and Samburu children. Participants' ages were estimated by parents and teachers.

2. All GLM coefficients reported here were log-transformed because a negative binomial model was used.

3. The model on the deviation of high-merit children's share from the equal split did not reveal a significant effect of age (estimate $=0.022, S E=0.015, p=.150$; see Table S3 in the Supplemental Material).

\section{References}

Adams, J. S. (1963). Towards an understanding of inequity. The Journal of Abnormal and Social Psychology, 67, 422-436. 
Almås, I., Cappelen, A. W., Sørensen, E. Ø., \& Tungodden, B. (2010). Fairness and the development of inequality acceptance. Science, 328, 1176-1178.

Baayen, R. H. (2008). Analyzing linguistic data: A practical introduction to statistics using $R$. Cambridge, England: Cambridge University Press.

Bates, D., Maechler, M., Bolker, B., \& Walker, S. (2013). lme4: Linear mixed-effects models using Eigen and S4 (R package version 1.0-5) [Computer software manual]. Retrieved from http://CRAN.R-project.org/package $=1 \mathrm{me} 4$

Baumard, N., Mascaro, O., \& Chevallier, C. (2012). Preschoolers are able to take merit into account when distributing goods. Developmental Psychology, 48, 492-498.

Cappelen, A. W., Sørensen, E. Ø., \& Tungodden, B. (2010). Responsibility for what? Fairness and individual responsibility. European Economic Review, 54, 429-441.

Carson, A. S., \& Banuazizi, A. (2008). "That's not fair": Similarities and differences in distributive justice reasoning between American and Filipino children. Journal of Cross-Cultural Psychology, 39, 493-514.

Chudek, M., \& Henrich, J. (2011). Culture-gene coevolution, norm-psychology and the emergence of human prosociality. Trends in Cognitive Sciences, 15, 218-226.

Damon, W. (1977). The social world of the child. San Francisco, CA: Jossey-Bass.

Dawes, C. T., Fowler, J. H., Johnson, T., McElreath, R., \& Smirnov, O. (2007). Egalitarian motives in humans. Nature, 446, 794-796.

Dobson, A. J. (2010). An introduction to generalized linear models. Boca Raton, FL: CRC Press.

Fehr, E., \& Gächter, S. (2000). Fairness and retaliation: The economics of reciprocity. Journal of Economic Perspectives, 14 , 159-181.

Fischer, R., \& Smith, P. B. (2003). Reward allocation and culture: A meta-analysis. Journal of Cross-Cultural Psychology, 34, 251-268.

Forstmeier, W., \& Schielzeth, H. (2011). Cryptic multiple hypotheses testing in linear models: Overestimated effect sizes and the winner's curse. Behavioral Ecology and Sociobiology, $65,47-55$.

Frohlich, N., Oppenheimer, J., \& Kurki, A. (2004). Modeling other-regarding preferences and an experimental test. Public Choice, 119, 91-117.

Gurven, M. (2004). To give and to give not: The behavioral ecology of human food transfers. Behavioral \& Brain Sciences, 27, 543-559.

Gurven, M., \& Winking, J. (2008). Collective action in action: Prosocial behavior in and out of the laboratory. American Anthropologist, 110, 179-190.

Hamann, K., Bender, J., \& Tomasello, M. (2014). Meritocratic sharing is based on collaboration in 3-year-olds. Developmental Psychology, 50, 121-128.

Henrich, J., Ensminger, J., McElreath, R., Barr, A., Barrett, C., Bolyanatz, A., . . . Ziker, J. (2010). Markets, religion, community size, and the evolution of fairness and punishment. Science, 327, 1480-1484.
Hook, J., \& Cook, T. D. (1979). Equity theory and the cognitive ability of children. Psychological Bulletin, 86, 429-445.

House, B. R., Silk, J. B., Henrich, J., Barrett, H. C., Scelza, B. A., Boyette, A. H., . . . Laurence, S. (2013). Ontogeny of prosocial behavior across diverse societies. Proceedings of the National Academy of Sciences, USA, 110, 14586-14591.

Kanngiesser, P., \& Warneken, F. (2012). Young children consider merit when sharing resources with others. PLOS ONE, 7(8), Article e43979. Retrieved from http://journals.plos .org/plosone/article?id=10.1371/journal. pone.0043979

Lane, I. M., \& Coon, R. C. (1972). Reward allocation in preschool children. Child Development, 43, 1382-1389.

Lesorogol, C. K. (2005). Experiments and ethnography: Combining methods for better understanding of behavior and change. Current Anthropology, 46, 129-136.

Marshall, G., Swift, A., Routh, D., \& Burgoyne, C. (1999). What is and what ought to be: Popular beliefs about distributive justice in thirteen countries. European Sociological Review, 15, 349-367.

McCullagh, P., \& Nelder, J. A. (2008). Generalized linear models. London, England: Chapman \& Hall.

Miller, C. E., \& Komorita, S. S. (1995). Reward allocation in task-performing groups. Journal of Personality and Social Psychology, 69, 80-90.

Murphy-Berman, V., Berman, J. J., Singh, P., Pachauri, A., \& Kumar, P. (1984). Factors affecting allocation to needy and meritorious recipients: A cross-cultural comparison. Journal of Personality and Social Psychology, 46, 1267-1272.

Nisan, M. (1984). Distributive justice and social norms. Child Development, 55, 1020-1029.

Oxoby, R. J., \& Spraggon, J. (2008). Mine and yours: Property rights in dictator games. Journal of Economic Behavior \& Organization, 65, 703-713. doi:10.1016/j.jebo .2005 .12 .006

Rawls, J. (1971). A theory of justice. Cambridge, MA: Harvard University Press.

R Development Core Team. (2013). R: A language and environment for statistical computing. Retrieved from http:// www.R-project.org/

Robinson, P. H., Kurzban, R., \& Jones, O. D. (2007). The origins of shared intuitions of justice. Vanderbilt Law Review, 60, 1633-1688.

Rochat, P., Dias, M. D. G., Liping, G., Broesch, T., PassosFerreira, C., Winning, A., \& Berg, B. (2009). Fairness in distributive justice by 3 - and 5-year-olds across seven cultures. Journal of Cross-Cultural Psychology, 40, 416-442.

Spencer, P. (2004). The Samburu: A study of gerontocracy. London, England: Routledge. (Original work published 1965)

Venables, W. N., \& Ripley, B. D. (2002). Modern applied statistics with $S$ (4th ed.). New York, NY: Springer.

Widlok, T. (1999). Living on Mangetti: 'Bushman' autonomy and Namibian independence. Oxford, England: Oxford University Press.

Woodburn, J. (1982). Egalitarian societies. Man, 17, 431-451. 